\title{
Information Sharing across Group Boundaries by Knowledge Brokers during a Disaster - Lessons for the Tourism Industry
}

\section{Fahimi Ali}

School of Business and IT, Wellington Institute of Technology, Wellington, New Zealand

\author{
Mohamad-Noor Salehhuddin Sharipudin \\ Kedah, Malaysia \\ Kim-Shyan Fam \\ Victoria University of Wellington, Wellington, New Zealand \\ Harbin University of Commerce, Harbin, China
}

School of Multimedia Technology and Communication, Universiti Utara Malaysia,

\begin{abstract}
During disasters, information sharing across group boundaries is seen as highly significant. It requires extensive information sharing flow between different groups and individuals in the community, and among the different response teams. People who receive and share information during a disaster are also known as knowledge brokers (KB). The importance of information sharing during a disaster has been discussed in both academic and practitioner. However, very little attention has been paid to the individual level. This study explored the nature of cross-group boundary information sharing by knowledge brokers during a disaster, specifically in New Zealand. Our objective was to identify how KB assesses the veracity of the information they receive and to whom the information is relevant during a disaster. We used multiple case studies via in-depth face-to-face interviews. Case studies were taken from past New Zealand disasters. The scenario experienced by the KB was the level of analysis. 10 different disasters involving 22 unique scenarios were analyzed. It was found that a $\mathrm{KB}$ went through two phases in deciding on the veracity and relevance of information they received. In both phases, KB received information across four types of boundaries and used different types of cognitive resources in the process.
\end{abstract}

Keywords: Information Sharing, Information Filtering, Information Veracity, Disaster Management, Tourism Industry, Knowledge Brokers

Publication Details: Received 29 Aug 2018; Revised 4 July 2019; Accepted 24 July 2019 


\section{Introduction}

In recent years, many disasters and major incidents have occurred around the world. For example, in the year 2017, there were 318 reported disasters with 9,503 people dead, 96 million people affected and US\$314 billion in economic damage (United Nation Office for Disaster Risk Reduction, 2016). From 2005 to 2014, 8 out of the 10 countries experiencing the most disasters were located in Asia, including 3 in South East Asia (i.e. Philippines, Indonesia and Vietnam) (United Nation Officer for Disaster Risk Reduction, n.d.).

There are different types of disasters with different degrees of impact such as earthquakes, bombs, bush fires, other fires, pandemics, terrorism, floods, tsunamis and other severe weather events (Bunker, 2010; Ehnis \& Bunker, 2013). Despite the differences between the disasters in many aspects, an important issue is the coordination and information sharing among disaster agencies during their response. On a global level, the United Nations (UN), under the United Nations Office for Disaster Risk Reduction (UNISDR), has adopted the Sendai Framework for Disaster Risk Reduction 2015-2030 after the third UN World Conference on Disaster Risk Reduction held in Sendai, Japan (United Nations, 2015). The framework has four main priority areas across local, national, regional and global levels: 1) Priority 1: Understanding disaster risk; 2) Priority 2: Strengthening disaster risk governance to manage disaster risk; 3) Priority 3: Investing in disaster risk reduction for resilience; and 4) Priority 4: Enhancing disaster preparedness for effective response and to "Build Back Better" in recovery, rehabilitation and reconstruction.

Information sharing initiatives which include coordination among multiple agencies at different levels have been recommended for all of the priorities. Coordination is "the way in which different agencies or parts of the same organization work or act together in order to achieve a common objective" (International Organization for Standardization, 2011). Information sharing in a disaster has been a central topic of discussion in major disasters locally and also globally for over 10 years. It is important that the information being shared is timely, relevant and accurate (Altay \& Pal, 2014). Reports have shown that one of the factors that hinder prevention or mitigation of disasters is the failure to share information between the decision makers of various agencies (Kramer, 2005). In New Zealand, the report by the Royal Commission on the Pike River Coal Mine Tragedy (2012) shows that information was not being shared between agencies with regard to the safety issues in the company that operated the coal mine which resulted in a deadly explosion that killed 29 employees. This shows how the lack of information sharing and coordination among agencies has a major impact. The people who manage the flow of information across different agencies are thus worthwhile studying. These people, who receive and share information between different groups, are known as 'knowledge brokers' (KB) (Meyer, 2010).

The following are the problem statements which lead to the motivation for conducting this research: i) Poor understanding of knowledge broker activities during a disaster (Ancona \& Caldwell, 1992; Fritsch \& Kauffeld-Monz, 2010; Guzzo \& Dickson, 1996; Meyer, 2010), ii) Lack of evidence about the process of cross-boundary information sharing at the individual level during a disaster (Altay \& Pal, 2014; Baber, Cross, Smith, \& Robinson, 2007) and iii) To improve information sharing 
practices in the tourism industry (Braun \& Hollick, 2006; Jiang \& Ritchie, 2017; Kim, Lee, Shin, \& Yang, 2017; Xiang \& Gretzel, 2010).

This research addresses two research objectives: i) to explore and identify the process of how KB assess the veracity of the information they receive from a source located across a boundary during a disaster and ii) to explore and identify the process of how $\mathrm{KB}$ assess to whom the information is relevant across a boundary during a disaster. To achieve these objectives, there are two research questions: i) how does KB assess the veracity of the information they receive from a source located across a boundary during a disaster? and ii) how does $\mathrm{KB}$ assess to whom the information is relevant across a boundary during a disaster?

Next, this research paper reviews literature of knowledge broker and information sharing across boundaries. Then, this paper discusses research method and findings. Finally, this paper discusses discussion and further research direction.

\section{Literature Review}

\section{Knowledge Brokers (KB)}

Knowledge brokers $(\mathrm{KB})$ have attracted considerable interest in the literature (Cranefield, Yoong, \& Huff, 2011; Kauffeld-Monz \& Fritsch, 2013; Kislov, Hodgson, \& Boaden, 2016; Meyer, 2010). This type of broker is defined as an actor that facilitates the transfer of knowledge within a social network (Meyer, 2010). The social network members can consist of groups (Burt, 2004), units (Pawlowski \& Robey, 2004) and organizations (Fritsch \& Kauffeld-Monz, 2010; (Cranefield, Yoong, \& Huff, 2011; Kauffeld-Monz \& Fritsch, 2013; Kislov, Hodgson, \& Boaden, 2016; Lind \& Persborn, 2000).

These studies argue that KB plays an important role in sharing information across their group boundaries. In the context of the impact on sharing information, KB might not gain any advantage from keeping the information to themselves because the information is only relevant to the recipient (Fritsch \& Kauffeld-Monz, 2010).

During a disaster, extensive information sharing flows between groups are required. KB might hold certain information that might be relevant to others. They also might share the information across their group boundary to members of different groups. These groups are responsible for managing the situation. Some examples of the groups that might be involved during a disaster are police, fire services, ambulance services and emergency offices. These groups may share information between them during a disaster for reasons such as collaborative decision making (Kapucu \& Garayev, 2011; Sitas, Reyers, Cundill, Prozesky, Nel, \& Esler 2016) or humanitarian operations (Altay \& Pal, 2014).

Many studies have explored the importance of inter-organization information sharing during emergency situations. Baber et al. (2007) for instance suggest the use of Geographical Information Systems (GIS) to make collaboration between agencies easier. Duffy, McMaster, Baber, and Houghton (2012) suggest the importance of having an ontology broker to analyze the information flow in communication 
channels during an emergency. Altay and Pal (2014) and Gossler, Wakolbinger, Nagurney, and Daniel (2019) discuss knowledge brokering during humanitarian operations. They suggested that during disaster responses, an information hub could make information diffusion faster.

While these studies discussed information sharing and knowledge brokering during disasters, they either focus on information systems as the KB (Baber et al., 2007; Duffy et al., 2012) or on knowledge brokering at the organizational level (Altay \& Pal, 2014; Schraagen, Veld, \& De Koning, 2010). Although research has been carried out at those levels, little attention has been given to $\mathrm{KB}$ at the individual level during disasters. These individual $\mathrm{KB}$ are the ones who critically manage the information flow during disasters.

\section{The Role of KB}

KB play an important role in disasters to assist critical decision making by those who are outside the KB's group and involved in the same situation. For example, a hotel manager could receive information from a tourist that a nearby hospital is in need of a generator during a power outage following an earthquake. The hotel manager is considered a KB as he obtains information from someone who is not an employee of the hotel (i.e. the tourist) and there is a possibility that the hotel manager might pass it to a different person who is also not a hotel employee for the facilitation of immediate supply of a generator (i.e. police or fire service). In that situation, the hotel manager is seen to be playing an important role to assist critical decision making by the police or fire service to arrange for the back-up generator.

Since there are very limited studies on $\mathrm{KB}$ roles during a disaster, this study uses studies from knowledge brokering in general to explore the roles of KB. There is a possible role of $\mathrm{KB}$ found in the literature: the boundary spanner.

\section{The Boundary Spanner}

At the organizational level, a boundary spanner has been defined as performing "actions to establish linkages and manage interactions with parties in the external environment" (Marrone, 2010, p. 914). KB span boundaries and act as intermediaries (Howells, 2006) by linking those who are involved in the innovation process and those who are across boundaries.

From a disaster management perspective, it is crucial for KB to be boundary spanners to influence the cross-boundary information sharing with different agencies (Janssen, Lee, Bharosa, \& Cresswell, 2010). Curnin, Owen, and Trist (2014) found that KB play a boundary spanning role as representatives, communicators, networkers, legitimate enablers, information conduits, information analysts, resource coordinators, organizational experts and domain experts. These studies highlight the importance of the role during disasters. 
While the literature has focused heavily on this role of $\mathrm{KB}$ in the context of information sharing across boundaries for organizational innovation purposes (Cillo, 2005; Howells, 2006; Kauffeld-Monz \& Fritsch, 2013), the role of boundary spanner can be seen as similar in disasters. This is because in disasters, although the nature of the information is different than in innovation, KB span boundaries and act as intermediaries by establishing linkages and managing interactions with different disaster agencies' members.

\section{Types of Boundaries}

"Boundaries at least partly define how a group needs to operate within its context to be effective" (Sundstrom, De Meuse, \& Futrell, 1990, p. 121). This research adopts the definition of boundary as an 'imaginary line of demarcation' that separates members from those who are outside (Guzzo \& Dickson, 1996). Many studies have discussed and identified the different boundaries of information sharing. These include team boundaries (Ancona \& Caldwell, 1992; Owen et al., 2013), organizational and group boundaries (Curnin \& Owen, 2014; Kapucu, 2012; Sundstrom et al., 1990).

In a disaster, information travels across different boundaries: within an organization such as units, departments or hierarchically (Schraagen et al., 2010; Sitas, Reyers, Cundill, Prozesky, Nel, \& Esler, 2016); across organizations such as different emergency response agencies (Bharosa, Lee, \& Janssen, 2010; Power, 2018) and from organization to community and from community to organization (Quarantelli, 1988).

Bharosa et al. (2010) study information sharing across multiple agencies during a disaster. They identify factors that affect the efficiency of inter-organizational information sharing at different levels such as the community level (e.g. structures and procedures); agency level (e.g. norms of information sharing and knowledge about other organizations' operations) and individual level (e.g. job responsibilities). Quarantelli (1988) identifies that information sharing between the community and the organizations involved in a disaster has often been done poorly. This is because organizations fail to understand what information the community needs and what it does not. These studies show that information travels across different types of boundaries during a disaster.

\section{Cross-boundary Information Sharing}

During a disaster, there is the need to cross the normal line of communication or information sharing protocols. The need to reduce bureaucracy arises in disasters as different decision makers will have to make decisions quickly. This means that the speed and accuracy of gathered information is critical. Bharosa et al. (2010) found that during disasters, individuals are aware of the importance of sharing information but often face challenges such as system usability, organizational norms and the emotional rewards that inhibit the intention to share information. Mendonça, Jefferson, and Harrald (2007) suggest that during a disaster, the line of communication should be more of an 'adhocracy' than bureaucracy. This is to make sure the information is being shared and reaches its target faster. Howard, Agllias, Bevis, and Blakemore (2017) suggest that different groups require different need and access to effective communication during a disaster. 
When KB receives the information from a source across their group's boundary, they have to decide the veracity of the information. Although trust plays an important role in information sharing during disasters (Janssen et al., 2010), the factors that lead to trust need to be explored. Even if KB trusts the information they received, sometimes $\mathrm{KB}$ will then pass the information to someone else. In this situation, KB "in one organization (e.g. fire brigade) decide what is relevant for another organization (e.g. police) without knowing enough to be able to decide whether or not the other organization really needs the information" (Bharosa et al., 2010, p. 62). Therefore, in order for KB to decide the veracity of the information they receive and to whom the information is most relevant, a reference to cognitive resources might be useful.

\section{Cognitive Resources}

Cognitive resources in this research comprise a person's memory and intelligence based on experience. KBs' cognitive resources are essential to assist with the processing of information that they received and share across different boundaries during disasters. Their cognitive resources make sense of the information they receive to give meaning to the information before sharing it with others (Orton \& Weick, 1990). Furthermore, inadequate cognitive resources may affect decision making (Khalid, Helander, \& Hood, 2013; Lieder, Griffiths, \& Hsu, 2018). Bharosa et al. (2010) found that KB does not have enough time and cognitive resources to absorb and process information that they receive during a disaster.

Fiedler and Garcia (1987) developed the cognitive resources theory. The theory focuses on leaders' intelligence and their experience in performing under a certain level of stress. They propose that intelligent leaders make more effective plans and strategies. Furthermore, the theory suggests that intelligence works better in a lowstress situation. In a more stressful situation, previous experience is more useful than intelligence (Fiedler, 2001).

There are different factors that can increase a person's cognitive resources. These include a set of rules (Bouquet \& Birkinshaw, 2008; Constant, Kiesler, \& Sproull, 1994; Groenendaal, Helsloot, \& Scholtens, 2013; Morrison \& Milliken, 2000), source credibility (Mayhorn \& McLaughlin, 2014; Pornpitakpan, 2004) and similar experience and training (Cunningham \& MacGregor, 2014; Maier, 1945; Mayhorn \& McLaughlin, 2014).

\section{Research Method}

\section{Methodological Perspective}

The objective of this study is to understand the phenomenon of how KB assesses the veracity and relevance of the information they received. This can be seen as trying to reveal the complex meanings of people. As discussed in the previous section, lack of knowledge in this area suggests that this phenomenon needs exploration and this research aims to contribute to the generation of new theory. The selection of the qualitative methodological perspective was also driven by the aim to provide thick description of KBs' real context (Creswell, 2003; Edmondson \& McManus, 2007; Miles \& Huberman, 1994). 


\section{Research Strategy: Case Research}

This study used case research. Yin (2009, p. 18) defined case research as "an empirical inquiry that investigates a contemporary phenomenon in depth and within its real-life context, especially when the boundaries between phenomenon and context are not clearly evident".

This study suited exploratory case research because little is known about how knowledge brokers make their decisions during a disaster (Alison et al., 2015; Bharosa et al., 2010; Gore, Flin, Stanton, \& Wong, 2015). The context of this study is any disaster that occurs in New Zealand. This includes earthquakes, flooding, tsunami, storms, landslides, drought, volcanic eruptions, pandemics, lifeline utility failures, hazardous substance incidents, transport accidents, bomb threats, terrorism and fires (Wellington Region Civil Defence Emergency Management, 2013). All of the disasters are suitable cases for investigating the study's research question because they provide a specific event.

The unit of analysis is the behavior of $\mathrm{KB}$. The behavior of $\mathrm{KB}$ in a disaster was captured through unique 'scenarios' or situations in every disaster. By doing this, it allows this study to understand the information sharing behavior of KB in each of the 'scenarios' of each disaster.

\section{Case Selection}

A snowball sampling method to identify the cases was employed after the first case was found. Ten different cases (i.e. disasters) were selected and analyzed. The disasters, taking place between 2001 and 2014, were identified and selected from five face-to-face interviews with five KB. The cases include (arranged in descending order of year): 1) 2014 Kilbirnie storage warehouse fire; 2) 2014 Pekapeka Road motor accident; 3) 2013 Wellington earthquake (August); 4) 2013 Wellington earthquake (July); 5) 2012 Otaihanga fatal motor vehicle accident; 6) 2010 Pike River mine explosion; 7) 2008 Paraparaumu mid-air collision; 8) 2008 Otaki Beach bush fire 9) 2008 Paraparaumu bomb in a house; 10) 2001 Aotea Quay Wellington fatal motor vehicle accident.

The selected ten cases also shared the following characteristics:

- The cases were experienced by KB whose information sharing behavior in each scenario of the case is the unit of analysis;

- Each of the cases has one to four unique scenarios that highlight the flow of information from receiving to sharing the information with someone else that relates to this study.

\section{Data Collection Procedures}

Based on the two research questions, a semi-structured interview script was used as it allows flexibility and improvisation (Myers \& Newman, 2007). It is also useful for exploration and leads to interesting rich information which will reduce uncertainty and clarify ambiguity (Daft \& Lengel, 1983, p. 5) and may lead to a deeper context of meanings and explanation that suits the exploratory nature of this research. 
The participants in this study have been selected from people who are or have been working in an emergency management and response organization in New Zealand. In this study interviews were conducted with five selected participants (i.e. KB) who provided ten vignettes (i.e. cases) with 22 scenarios (i.e. unit of analysis).

\section{Data Analysis Procedures}

For ensuring a high standard of data analysis, Yin (2009) has outlined the following four basic principles: first, attend to all evidence (i.e. the data); second, address all major rival interpretations (i.e. all similar findings and interpretations by other scholars are discussed); third, address the most significant aspect of this study; and fourth, use one's own prior expert knowledge. This study followed all four principles and analyzed the data in two stages.

In stage one, the chronology of the events was established, then coded after which themes emerged - filtering and matching the information. In stage two, cases were written in vignettes. A vignette is one of the methods of describing data, especially actions. They are a "focused description of a series of events taken to be representative, typical or emblematic in the case you are studying" (Miles, Huberman, $\&$ Saldaña, 2014, p. 182). The vignettes were written so that the reader can imagine what happened during the disaster from the viewpoint of the $\mathrm{KB}$ who was interviewed. Each vignette represents a case (i.e. disaster). Since ten cases were identified from the five $\mathrm{KB}$, there are ten vignettes in total. Each vignette has one to four unique scenarios that comprise the information sharing behavior of $\mathrm{KB}$.

In ensuring the trustworthiness of this study, a well-cited guideline by Guba (1981) was followed which comprises four factors: credibility, transferability, dependability and conformability. For credibility, member checking was conducted and approval gained from the Human Ethics Committee. For transferability, case boundaries were made clear. For dependability, the study's research methods are described in great detail. Finally, conformability was achieved by providing a detailed description of data collection and analysis.

\section{Research Findings}

\section{Stage 1 Analysis}

There are two phases of information flow that knowledge brokers (KB) experience during a disaster: Phase one, the filtering phase to assess the information's veracity; and Phase two, the matching phase when they recall an experience and match the information to the relevant people.

\section{Phase One - The Filtering Process}

In Phase one, the process starts when $\mathrm{KB}$ receive information from a source located across a boundary. Then KB filters the information they received before making the decision on the information's veracity. The process in Phase one ends when KB decide whether the information is true or false. For example, in V1S1, KB1 received information from a source who was his subordinate (i.e. a fire officer), to call in a 
helicopter for additional help in controlling the fire. KB1 then filtered the information and decided to trust the information source and decided that the information was true (see Error! Reference source not found.).

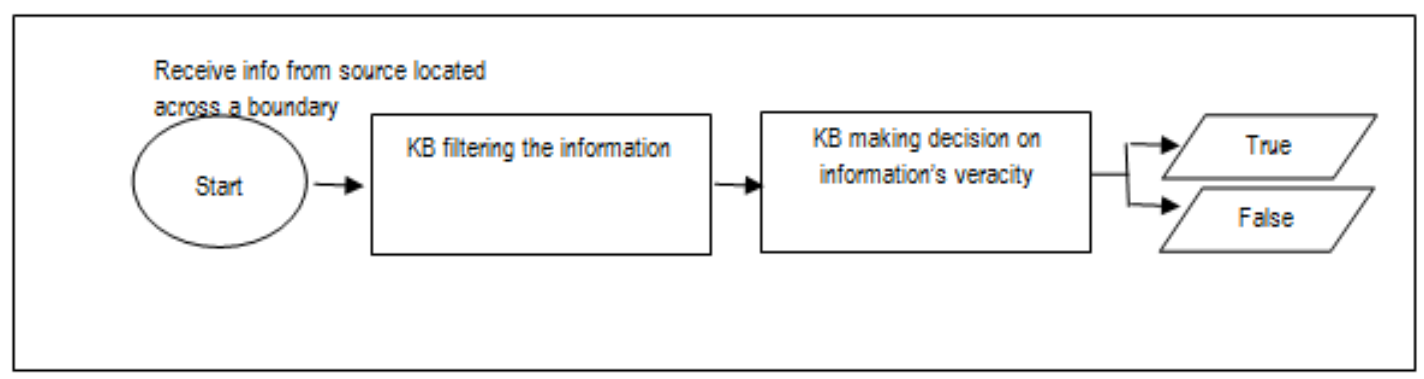

Figure 1: Phase One - Filtering Process

When KB has decided on the veracity of the information they received, a second process follows: Phase two.

\section{Phase Two - The Matching Process}

The process starts immediately following the end of Phase one, when KB has decided on the veracity of the information they received from a source located across a boundary. In this phase, the process starts when $\mathrm{KB}$ recall previous experience to match the information with the relevant receiver. Then KB decides to whom the information is relevant. The process in this phase ends when KB make the decision to either share the information with a receiver located across a boundary or to keep the information to them.

Using V1S1, the process starts immediately following the end of Phase one when $\mathrm{KB} 1$ decided that the information was true. KB 1 recalled his previous experience and matched the information with the relevant receiver. The process ends when KB1 decides to share the information with the Fire Communication unit (see Figure 2).

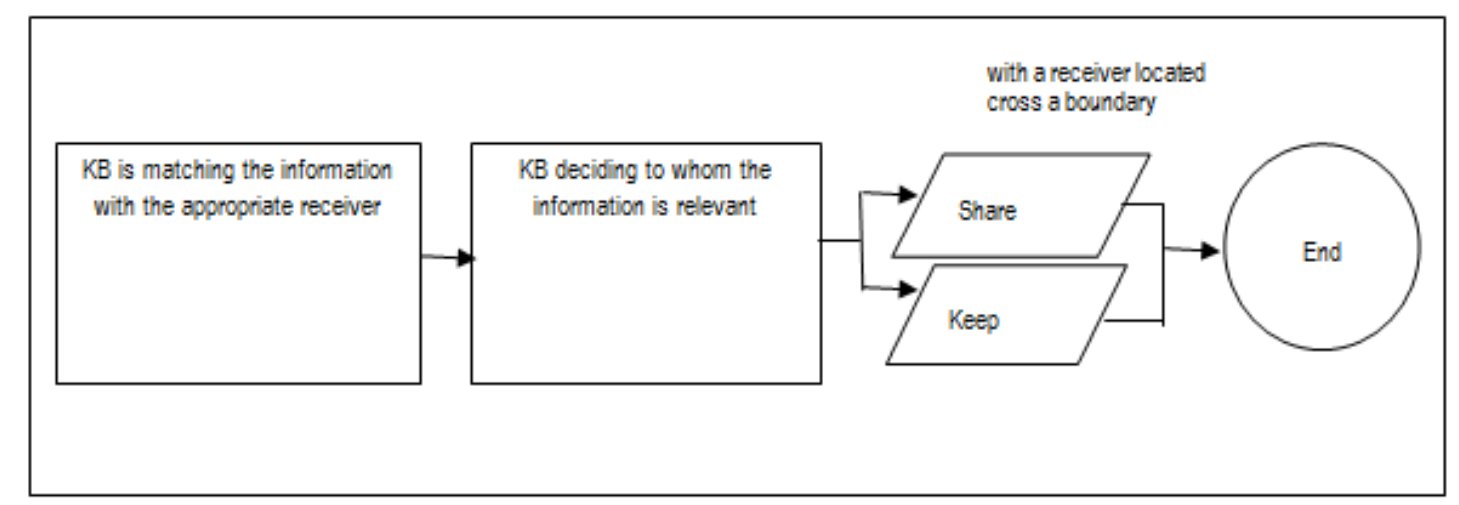

Figure 2: Phase Two - Matching Process 


\section{Stage 2 Analysis}

\section{Types of Boundary}

Based on the 22 scenarios, KB received information from across four types of boundaries. These are hierarchical, unit, organization and community. An example of a type of boundary, the definition and its evidence is provided in Error! Reference source not found..

Table 1: Example of a Type of Boundary

\begin{tabular}{|l|l|l|}
\hline Boundary type & \multicolumn{1}{|c|}{ Definition } & \multicolumn{1}{c|}{ Evidence } \\
\hline Hierarchical & $\begin{array}{l}\text { Those who work in the same } \\
\text { organization but have different } \\
\text { levels of authority }\end{array}$ & $\begin{array}{l}\text { "...I actually get a call [from the senior } \\
\text { fire-fighter who is a subordinate]... } \\
\text { (VIS1) }\end{array}$ \\
\hline
\end{tabular}

\section{Types of Information}

Based on the 22 scenarios, $\mathrm{KB}$ received the following seven types of information from a source located across a boundary: request, recommendation, and update, investigative, notification, advisory and informative. An example of a type of information, the definition and its evidence is given in

Table 2: Types of Information

\begin{tabular}{|l|l|l|}
\hline Type of information & \multicolumn{1}{|c|}{ Definition } & \multicolumn{1}{c|}{ Evidence } \\
\hline Recommendation & $\begin{array}{l}\text { Suggesting an action to } \\
\text { solve a problem }\end{array}$ & $\begin{array}{l}\text { “... I actually get a call [from the senior } \\
\text { firefighter who is a subordinate] over } \\
\text { the radio while I was en route to the } \\
\text { [disaster] recommending that the } \\
\text { helicopter [is to be] paged...” }\end{array}$ \\
& &
\end{tabular}

\section{Cognitive Resources}

KB filters the information they receive by relying on their cognitive resources. The cognitive resources found include: the process of having confidence in the source's credibility, having social ties with the source, triangulating the information, following a set of rules, having insider knowledge, recalling previous experience and scanning for vested interests. Two examples of the cognitive resources, the definition and the evidence are listed in Error! Reference source not found..

Table 3: Cognitive Resources in Phase 1

\begin{tabular}{|l|l|l|l|}
\hline$\#$ & \multicolumn{1}{|c|}{$\begin{array}{c}\text { Cognitive } \\
\text { resources }\end{array}$} & \multicolumn{1}{|c|}{ Definition } & \multicolumn{1}{c|}{ Evidence } \\
\hline 1 & $\begin{array}{l}\text { Having } \\
\text { confidence in the } \\
\text { source's } \\
\text { credibility }\end{array}$ & $\begin{array}{l}\text { Any situation during the } \\
\text { incident where the KB is } \\
\text { confident about the information } \\
\text { source's credibility due to the } \\
\text { source's credible past } \\
\text { experience or the credibility of } \\
\text { the organization that the source }\end{array}$ & $\begin{array}{l}\text { "Those guys in the brigade have } \\
\text { got 20-odd years of fire } \\
\text { experience, dealing with rural } \\
\text { fires...So, I definitely refer to } \\
\text { their advice and } \\
\text { recommendations" (V1S1) }\end{array}$ \\
\hline
\end{tabular}




\begin{tabular}{|l|l|l|l|}
\hline & belongs to & \\
\hline 2 & $\begin{array}{l}\text { Having social ties } \\
\text { with the source }\end{array}$ & $\begin{array}{l}\text { Any situation during the } \\
\text { incident where the KB knows } \\
\text { the information source and has } \\
\text { a certain degree of relationship } \\
\text { with them }\end{array}$ & $\begin{array}{l}\text { "I knew the senior fire fighters] } \\
\text { probably 6 months before the } \\
\text { fire happened and there was just } \\
\text { enough time to oversee a little } \\
\text { bit of relationships with those } \\
\text { key individuals"(V1S1) }\end{array}$ \\
\hline
\end{tabular}

\section{Stage 2 analysis}

\section{Cognitive Resources}

The process in Phase two starts when KB matches the information they hold with the relevant person by relying on several cognitive resources. The cognitive resources include: being asked by someone, recalling training, having social ties, following a set of rules, following the organizational structure and recalling previous experience. Two examples of the cognitive resources, the definition and the evidence are below in Error! Reference source not found.

Table 4: Cognitive Resources in Phase 1

\begin{tabular}{|l|l|l|l|}
\hline$\#$ & \multicolumn{1}{|c|}{ Cognitive resource } & \multicolumn{1}{|c|}{ Definition } & \multicolumn{1}{c|}{ Evidence } \\
\hline 1 & Being asked by someone & $\begin{array}{l}\text { Any situation during the } \\
\text { incident where the KB } \\
\text { knows to whom the } \\
\text { information is relevant } \\
\text { after being asked by the } \\
\text { information seeker }\end{array}$ & $\begin{array}{l}\text { "...the ambulance had asked us } \\
\text { when we were there..." (V6S2) }\end{array}$ \\
\hline 2 & Recalling training & $\begin{array}{l}\text { Any situation during the } \\
\text { incident where the KB } \\
\text { knows to whom the } \\
\text { information is relevant } \\
\text { after the KB recalls the } \\
\text { training they had relating to } \\
\text { the situation }\end{array}$ & $\begin{array}{l}\text { "That is part of the training } \\
\text { programme that the } \text { RNFA provides } \\
\text { to fire officers, when you first go } \\
\text { through an induction programme as } \\
\text { a Rural Fire Officer..." (VIS3). }\end{array}$ \\
\hline
\end{tabular}

After KB matches the information they hold using their cognitive resources, they then decide to whom the information is relevant. KB then decide either to share the information with a receiver located across a boundary or to keep the information to themselves if they could not identify to whom the information was relevant at that time.

\section{Types of boundary}

When KB shares the information with the receiver, they share across boundaries. The types of boundaries that $\mathrm{KB}$ share across are similar to the types of boundaries in Phase one: hierarchical, unit, organization and community.

\section{Types of information}

The types of information shared are also similar to those in Phase two: request, recommendation, and update, investigative, notification, advisory and informative. 
To summarize the findings, if both of the phases' findings are combined, the information flow will look like Figure 4 below. The theoretical model shows a coordinated process of information flow that KB receives and share. This includes the cognitive resources used both to filter the information and match to whom it is relevant.

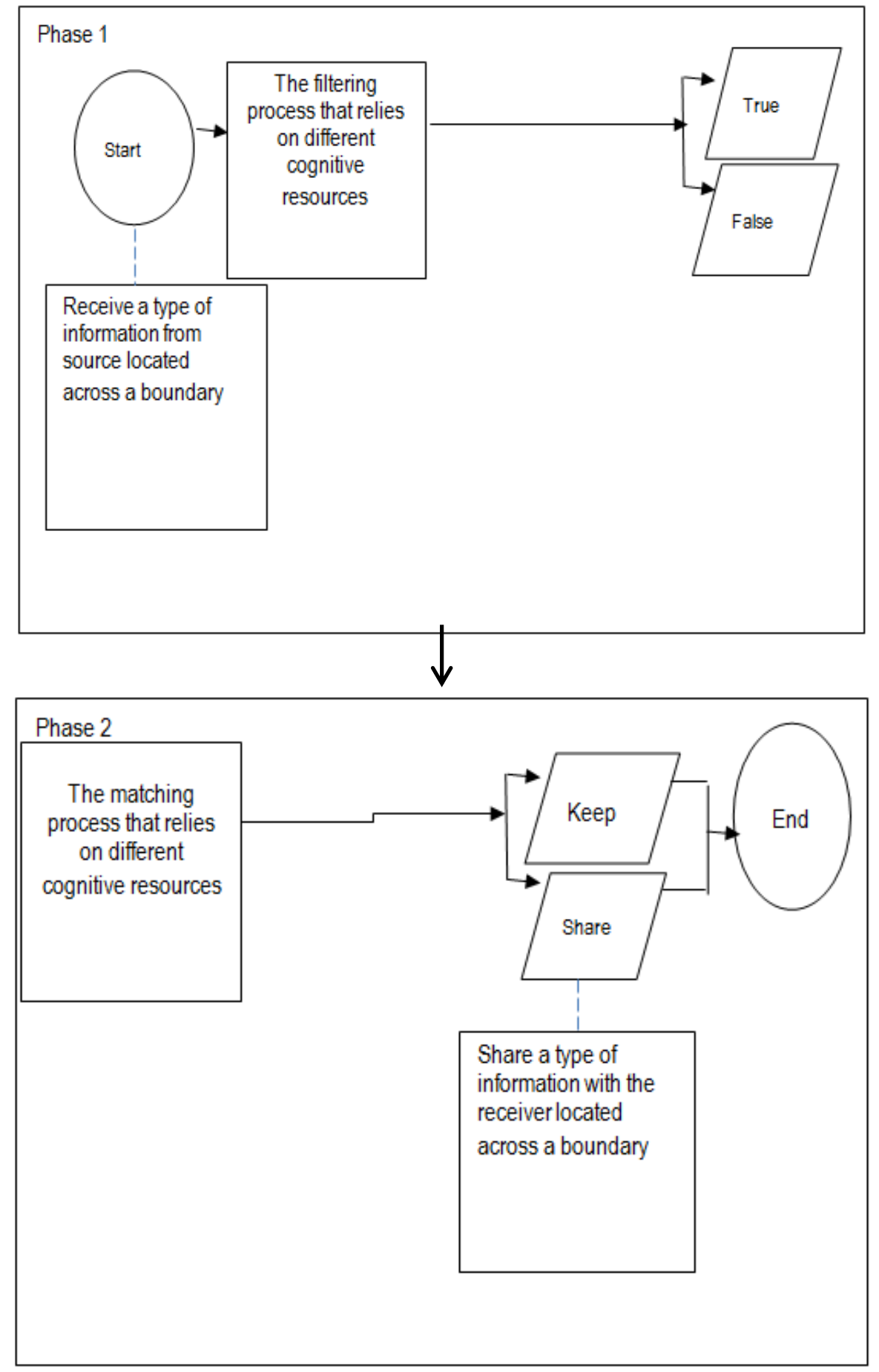

Figure 3: Theoretical Model: Information Sharing across Group Boundaries by Knowledge Brokers during a Disaster 


\section{Discussion}

\section{Implication to Theory}

Marrone (2010) has identified that KB play the role of a boundary spanner. A boundary spanner "perform actions to establish linkages and manage interactions with parties in the external environment" (p. 914). She proposed a multilevel model of boundary spanning - member, team and network - as a bottom-up (vertical) process. This research supports this idea where KB plays a boundary spanner role through a hierarchical (member) boundary as a vertical process. In addition, this research also found that $\mathrm{KB}$ play a boundary spanner role across other boundaries such as unit (team), organizational (network) and community (network) boundaries, not in a vertical process but in a horizontal process. This extends Marrone's (2010) proposed multilevel model of boundary spanning from not only a vertical process but also to a horizontal process. The extension does not mean a considerable change to the model, but merely provides a context where KB plays a boundary spanner role across team and network boundaries as a horizontal process during a disaster.

In the disaster management area, particularly in the information sharing during disasters literature, scholars found that there are some challenges at the individual level when sharing information. Bharosa et al. (2010) for example, found that information sharing across organizational boundaries failed despite people having good intentions to share. They also suggest that "it is very difficult to predict which information is relevant and which is not" (p. 63). Alison et al. (2015) found that information sharing across different organizational boundaries decreased during a disaster and some failed to make a decision - a situation called 'decision inertia'. This research found no evidence that $\mathrm{KB}$ is facing those challenges. $\mathrm{KB}$ was sharing information with a receiver located across an organizational boundary in most of the scenarios in Phase 2. However, this does not mean that the challenges and issues of information sharing across organizational boundaries were non-existent during disasters, merely that no evidence was found in this research to support the findings in the literature. Further, this research settings were based in New Zealand and the situation could potentially differ from Bharosa et al. (2010) whose research settings were in the Netherlands.

Bharosa et al. (2010) also found that the main issues facing the KB at the individual level are that they did not have enough time and cognitive resources to process all information received during a disaster. This research refines this idea. Although this research did not focus on challenges in information sharing during a disaster, the idea of cognitive resources was used. Several cognitive resources were found in both phases (i.e. Phase 1 and Phase 2). In Phase 1, this research found seven cognitive resources that $\mathrm{KB}$ relies on to filter the information they received. They are: feeling confidence in the source's credibility, having social ties with the source, triangulating the information, following a set of rules, having insider knowledge, recalling previous experience and scanning for vested interests. In Phase 2, six cognitive resources were found: being asked by someone, recalling the training, having social ties with the information receiver, following a set of rules, following the organizational structure, and recalling previous experience. $\mathrm{KB}$ was relying on these cognitive resources to filter and match the information that they have with a receiver. 
In summary, this research has contributed to the disaster management area as no evidence were found of challenges that $\mathrm{KB}$ faced in sharing information across an organizational boundary and refines the idea of the usage of cognitive resources in making the decision to share information across a boundary during a disaster.

\section{Implications for Practice}

The nature of this research also includes providing useful contributions for government agencies and practitioners involved in tourism and hospitality industries. This study intends to provide a few contributions to assist government agencies as well as tourism and hospitality practitioners to disseminate information during a disaster. It could be argued that the failure of sharing information among government agencies and relevant parties could contribute to a major crisis during a disaster (Kramer, 2005). For instance, the report by the Royal Commission on the Pike River Coal Mine Tragedy (2012) in New Zealand states that the lack of information sharing about safety issues among the government agencies and relevant parties had led to the deaths of 29 coal mining employees.

Disaster can happen at any time. In order to avoid any issues and tragedies, this study proposes a theoretical model that can be applied during a disaster. This model explains how knowledge brokers $(\mathrm{KB})$ receives the information and shares it with the relevant agencies during a disaster. For instance, based on the Phase 1 of the model, $\mathrm{KB}$ who involved heavily in disaster management could have an idea of how to verify the information that they received quickly and how to make a decision to clarify the veracity of the information during a disaster. Time is very vital especially during a disaster and $\mathrm{KB}$ needs to ensure that the information is true or false before moving to the next phase. If the information is true, KB might follow the Phase 2 model in order to share the information.

This study proposes Phase 2 of the model which is related to what KB needs to do after they have found that the information is true. As discussed earlier, this is an extremely important action to be taken during a disaster when the government agencies are reluctant to share the information that they have received to the other relevant parties especially the ones across the boundary. Instead of keeping the important information, KB might share the information not only within their network, but also across the boundary.

In terms of practitioners' point of view, the model can be used as a training module for KB. Any government agencies who are involved in disaster management could use this module to train the potential KB in their organisations. Therefore, the KB should have the knowledge about how to manage the information and share it with the relevant parties especially during a disaster. When a disaster occurs, the KB knows how to verify and disseminate the information quickly to other parties across the boundaries.

In addition, this study offers an idea for the government agencies with respect to providing a platform for $\mathrm{KB}$ to channel and share their information during a disaster with the relevant agencies such as the Civil Defense, Ministry of Foreign Affairs, and Ministry of Tourism. The authenticity of the information will be validated by the KB 
(Lee, Low \& Low, 2019). Hence, the relevant government agencies can access the information and disseminate it to the relevant parties immediately.

In terms of tourism industry, the platform could be useful in gathering the information especially during a disaster. For example, the Ministry of Tourism could use the platform for tourism and hospitality practitioners such as hoteliers, airlines, tour operators, and visitors to access credible information related to disasters. It will be great if the Ministry of Tourism could encourage visitors or tourists to subscribe to an information portal to channel any news or information pertaining to disasters. Therefore, it could help ease the uncertainty about a situation especially during a disaster when the industry players and public get the accurate information directly from the portal established by the Ministry of Tourism.

\section{Research Limitations}

The main limitation of this study is the lack of generalizability (Yin, 2009) which is common to qualitative case research. The findings could not be generalized to a wider range of disasters. Although there are ten cases with 22 unique scenarios, there is a need to have a larger set of units of analysis (i.e. unique scenarios). These scenarios can also be seen as part of a larger set of scenarios with a larger and diverse range of disasters. However, necessary steps have been taken to mitigate this limitation and ensure the quality and trustworthiness of this study and having different types of disaster in ten cases (i.e. vignettes).

Second, the KB who are the participants of this research are limited to senior emergency services personnel such as emergency management advisor, district police chief, fire officer, principal rural fire officer, local council emergency advisor and head of national emergency service coordination. Some cases were from the same KB who had experienced different disasters, which may affect the information flow. It would be more interesting if $\mathrm{KB}$ is from a wider group of people from non-emergency service organizations such as community leader, student leader or frontline officers.

Third, the applicability of the theory to all types of disaster is limited. Since the theory was developed based on the evidence from six types of disasters - fire, earthquake, mine explosion, mid-air collision, bomb in a house and motor accident - it may have been different if more types of disaster were included in the research. Other factors such as the degree of the disaster's geographical and social impact may also have affected the results of this research.

Fourth, the theory may not apply to other geographical locations. All of the scenarios have occurred in the Greater Wellington region (except for Pike River Mine explosion). Therefore, the $\mathrm{KB}$ responses to the interview are likely to be affected by different experience and training as compared to other locations. 


\section{Further Research Directions}

The disaster management literature includes various sub-topics. Some of them are system and technology development, decision-making training and disaster preparation. This study contributes to a wide range of sub-topics. For example, the system and technological development area could use these findings to develop a system for the decision maker to use during a disaster. The decision-making trainers could use it for the development of a training module and syllabus. In addition, the tourism industry can use this model to train their personnel during a disaster. Tourists rely heavily on updates from a credible source during a disaster.

Future research can confirm and refine the theory presented in this research. Researchers can verify the cognitive resources found in both phases (i.e. Phase one and Phase two). This means that investigating and comparing different types of disasters using the theory found in this research would be worthwhile.

It would also be possible in future research to test the theory that was developed in this study. Testing can be done through experiments, disaster simulation exercises or surveys.

This paper was presented in the MAG Scholar Conference 2018, Sarawak, Malaysia.

\section{References}

Alison, L., Power, N., Heuvel, C., Humann, M., Palasinksi, M., \& Crego, J., (2015), Decision inertia: Deciding between least worst outcomes in emergency responses to disasters, Journal of Occupational and Organizational Psychology, vol. 88, no. 2, pp. 295-321.

Altay, N., \& Pal, R., (2014), Information diffusion among agents: Implications for humanitarian operations, Production and Operations Management, vol. 23, no. 6, pp. 1015-1027.

Ancona, D., \& Caldwell, D., (1992), Bridging the boundary: External activity and performance in organizational teams, Administrative Science Quarterly, vol. 37, no. 4, pp. 634-665.

Baber, C., Cross, J., Smith, P., \& Robinson, D., (2007), Supporting implicit coordination between distributed teams in disaster management, In Löffler, J., \& Klann, M., (2007), Mobile Response, Springer Berlin Heidelberg.

Bharosa, N., Lee, J., \& Janssen, M., (2010), Challenges and obstacles in sharing and coordinating information during multi-agency disaster response: Propositions from field exercises, Information Systems Frontiers, vol. 12, no. 1, pp. 49-65.

Bouquet, C., \& Birkinshaw, J., (2008), Weight versus voice: How foreign subsidiaries gain attention from corporate headquarters, Academy of Management Journal, vol. 51, no. 3, pp. 577-601.

Braun, P., \& Hollick, M., (2006), Tourism skills delivery: Sharing tourism knowledge online, Education and Training, vol. 48, no. 8/9, pp. 693-703.

Bunker, D., (2010), Information systems management (ISM): Repertoires of collaboration for community warning $(\mathrm{CW})$ and emergency incident response (EIR), Paper presented at the International Conference Technologies for Homeland Security (HST), 2010 IEEE on 8 November 2010.

Burt, R. S., (2004), Structural holes and good ideas, American Journal of Sociology, vol. 110, no. 2, pp. 349-399. 
Cillo, P., (2005), Fostering market knowledge use in innovation: The role of internal brokers, European Management Journal, vol. 23, no. 4, pp. 404-412.

Constant, D., Kiesler, S., \& Sproull, L., (1994), What's mine is ours, or is it? A study of attitudes about information sharing, Information Systems Research, vol. 5, no. 4, pp. 400-421.

Cranefield, J., Yoong, P., \& Huff, S., (2011), "Driving change through brokering practices in an online community ecosystem", Retrieved from http://www.pacis net.org/file/2 011/PACIS2011-041.pdf

Creswell, J. W., (2003), Research design: Qualitative, quantitative, and mixed methods approaches, Sage Publications.

Cunningham, J. B., \& MacGregor, J. N., (2014), Productive and re-productive: Thinking in solving insight problems, The Journal of Creative Behavior, vol. 48, no. 1, pp. 44-63.

Curnin, S., \& Owen, C., (2014), Spanning organizational boundaries in emergency management, International Journal of Public Administration, vol. 37, no. 5, pp. 259270.

Curnin, S., Owen, C., \& Trist, C., (2014), Managing the constraints of boundary spanning in emergency management, Cognition, Technology \& Work, vol. 16, no. 4, pp. 549-563.

Daft, R. L., \& Lengel, R. H., (1983), "Information richness: A new approach to managerial behavior and organization design", Retrieved from http://www.dtic.mil/dtic/tr/fulltex t/u2/a128980.pdf

Duffy, T., McMaster, R., Baber, C., \& Houghton, R., (2012), Towards an ontology broker to improve cross-agency sharing in emergency response, Paper presented at the Proceedings of the 9th International ISCRAM Conference, Vancouver, Canada.

Edmondson, A. C., \& McManus, S. E., (2007), Methodological fit in management field research, Academy of Management Review, vol. 32, no. 4, pp. 1246-1264.

Ehnis, C., \& Bunker, D., (2013), The impact of disaster typology on social media use by emergency services agencies: The case of the Boston marathon bombing, Paper presented at the 24th Australasian Conference on Information Systems (ACIS).

Fiedler, F. E., (2001), When IQ+ experience = performance, Leadership \& Organization Development Journal, vol. 22, no. 3, pp. 132-139.

Fiedler, F. E., \& Garcia, J. E., (1987), New approaches to effective leadership: Cognitive resources and organizational performance, John Wiley \& Sons.

Fritsch, M., \& Kauffeld-Monz, M., (2010), The impact of network structure on knowledge transfer: An application of social network analysis in the context of regional innovation networks, The Annals of Regional Science, vol. 44, no. 1, pp. 21-38.

Gore, J., Flin, R., Stanton, N., \& Wong, B., (2015), Applications for naturalistic decisionmaking, Journal of Occupational and Organizational Psychology, vol. 88, no. 2, pp. 223-230.

Groenendaal, J., Helsloot, I., \& Scholtens, A., (2013), A critical examination of the assumptions regarding centralized coordination in large-scale emergency situations, Journal of Homeland Security and Emergency Management, vol. 10, no. 1, pp. 113135.

Gossler, T., Wakolbinger, T., Nagurney, A., \& Daniele, P., (2019), How to increase the impact of disaster relief: A study of transportation rates, framework agreements and product distribution, European Journal of Operational Research, vol. 274, no. 1, pp. 126-141.

Guba, E. G., (1981), Criteria for assessing the trustworthiness of naturalistic inquiries, Educational Technology Research and Development, vol. 29, no. 2, pp. 75-91.

Guzzo, R. A., \& Dickson, M. W., (1996), Teams in organizations: Recent research on performance and effectiveness, Annual Review of Psychology, vol. 47, no. 1, pp. 307338.

Howells, J., (2006), Intermediation and the role of intermediaries in innovation, Research Policy, vol. 35, no. 5, pp. 715-728. 
Howard, A., Agllias, K., Bevis, M., \& Blakemore, T., (2017), "They'll tell us when to evacuate": The experiences and expectations of disaster-related communication in vulnerable groups, International Journal of Disaster Risk Reduction, vol. 22, pp. 139146.

International Organization for Standardization, (2011), "ISO 22320:2011: Societal securityemergency management-requirements for incident response", Retrieved from https://www.iso.org/obp/ui/\#iso:std:iso:22320:ed-1:v1:en

Janssen, M., Lee, J., Bharosa, N., \& Cresswell, A., (2010), Advances in multi-agency disaster management: Key elements in disaster research, Information Systems Frontiers, vol. 12, no. 1, pp. 1-7.

Jiang, Y., \& Ritchie, B. W., (2017), Disaster collaboration in tourism: Motives, impediments and success factors, Journal of Hospitality and Tourism Management, vol. 31, no. 2, pp. 70-82.

Kapucu, N., (2012), Disaster and emergency management systems in urban areas, Cities, vol. 29 , pp. S41-S49.

Kapucu, N., \& Garayev, V., (2011), Collaborative decision-making in emergency and disaster management, International Journal of Public Administration, vol. 34, no. 6, pp. 366375.

Kauffeld-Monz, M., \& Fritsch, M., (2013), Who are the knowledge brokers in regional systems of innovation? A multi-actor network analysis, Regional Studies, vol. 47, no. 5, pp. 669-685.

Khalid, H. M., Helander, M. G., \& Hood, N. A., (2013), Visualizing disaster attitudes resulting from terrorist activities, Applied Ergonomics, vol. 44, no. 5, pp. 671-679.

Kim, S. E., Lee, K. Y., Shin, S. I., \& Yang, S. B., (2017), Effects of tourism information quality in social media on destination image formation: The case of Sina Weibo, Information \& Management, vol. 54, no. 6, pp. 687-702.

Kislov, R., Hodgson, D., \& Boaden, R., (2016), Professionals as knowledge brokers: The limits of authority in healthcare collaboration, Public Administration, vol. 94, no. 2, pp. 472-489.

Kramer, R. M., (2005), A failure to communicate: $9 / 11$ and the tragedy of the informational commons, International Public Management Journal, vol. 8, no. 3, pp. 397-416.

Lee, Y., Low, S., \& Low, C., (2019), Authenticity and commodification: A visual analysis of p2p tourism accommodation listing page, Asian Journal of Business Research, vol. 9, no. 1, pp. 21-35.

Lieder, F., Griffiths, T. L., \& Hsu, M., (2018), Overrepresentation of extreme events in decision making reflects rational use of cognitive resources, Psychological Review, vol. 125 , no. 1 , pp. 1-32.

Lind, M., \& Persborn, M., (2000), Possibilities and risks with a knowledge broker in the knowledge transfer process, Paper presented at the 42nd Annual Conference of the Operational Research Society.

Maier, N. R., (1945), Reasoning in humans. III. The mechanisms of equivalent stimuli and of reasoning, Journal of Experimental Psychology, vol. 35, no. 5, pp. 349-360.

Marrone, J. A., (2010), Team boundary spanning: A multilevel review of past research and proposals for the future, Journal of Management, vol. 36, no. 4, pp. 911-940.

Mayhorn, C. B., \& McLaughlin, A. C., (2014), Warning the world of extreme events: A global perspective on risk communication for natural and technological disaster, Safety Science, vol. 61, pp. 43-50.

Mendonça, D., Jefferson, T., \& Harrald, J., (2007), Collaborative adhocracies and mix-andmatch technologies in emergency management, Communications of the ACM, vol. 50, no. 3, pp. 44-49.

Meyer, M., (2010), The rise of the knowledge broker, Science Communication, vol. 32, no. 1, pp. 118-127.

Miles, M. B., \& Huberman, A. M., (1994), Qualitative data analysis: An expanded sourcebook, Sage Publications. 
Miles, M. B., Huberman, A. M., \& Saldaña, J., (2014), Qualitative data analysis: A methods sourcebook, Sage Publications.

Morrison, E. W., \& Milliken, F. J., (2000), Organizational silence: A barrier to change and development in a pluralistic world, The Academy of Management Review, vol. 25, no. 4, pp. 706-725.

Myers, M. D., \& Newman, M., (2007), The qualitative interview in IS research: Examining the craft, Information and Organization, vol. 17, no. 1, pp. 2-26.

Orton, J. D., \& Weick, K. E., (1990), Loosely coupled systems: A reconceptualization, Academy of Management Review, vol. 15, no. 2, pp. 203-223.

Owen, C., Bearman, C., Brooks, B., Chapman, J., Paton, D., \& Hossain, L., (2013), Developing a research framework for complex multi-team coordination in emergency management, International Journal of Emergency Management, vol. 9, no. 1, pp. 117.

Pawlowski, S. D., \& Robey, D., (2004), Bridging user organizations: Knowledge brokering and the work of information technology professionals, MIS Quarterly, vol. 28, no. 4, pp. 645-672.

Pornpitakpan, C., (2004), The persuasiveness of source credibility: A critical review of five decades' evidence, Journal of Applied Social Psychology, vol. 34, no. 2, pp. 243-281.

Power, N., (2018), Extreme teams: Toward a greater understanding of multiagency teamwork during major emergencies and disasters, American Psychologist, vol. 73, no. 4, pp. 478-490.

Quarantelli, E., (1988), Disaster crisis management: A summary of research findings, Journal of Management Studies, vol. 25, no. 4, pp. 373-385.

Schraagen, J. M., Veld, M. H., \& De Koning, L., (2010), Information sharing during crisis management in hierarchical vs. network teams, Journal of Contingencies and Crisis Management, vol. 18, no. 2, pp. 117-127.

Sitas, N., Reyers, B., Cundill, G., Prozesky, H. E., Nel, J. L., \& Esler, K. J., (2016), Fostering collaboration for knowledge and action in disaster management in South Africa, Current Opinion in Environmental Sustainability, vol. 19, pp. 94-102.

Sundstrom, E., De Meuse, K. P., \& Futrell, D., (1990), Work teams, American Psychologist, vol. 45 , no. 2, pp. 120-133.

United Nation Office for Disaster Risk Reduction, (2016), "Natural disasters in 2017: Lower mortality, higher cost", Retrieved from https://www.preventionweb.net/publicati ons/view/57791

United Nation Officer for Disaster Risk Reduction, (n.d.), "Disaster statistics", Retrieved from https://www.unisdr.org/we/inform/disaster-statistics

United Nations, (2015), "Sendai framework for disaster risk reduction 2015 - 2030", Retrieved from http://www.preventionweb.net/files/43291_sendaiframeworkfordrre n.pdf

Wellington Region Civil Defence Emergency Management, (2013), “Group plan 2013-2018”, Retrieved from http://www.getprepared.org.nz/sites/default/files/uploads/2013\%20\%202018\%20Group\%20Plan.pdf

Xiang, Z., \& Gretzel, U., (2010), Role of social media in online travel information search, Tourism Management, vol. 31, no. 2, pp. 179-188.

Yin, R. K., (2009), Case study research: Design and methods, Sage Publications. 